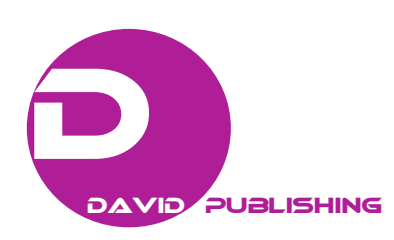

\title{
Reducing Carbon Emission through Container Shipment Consolidation and Optimization
}

\author{
Nang Laik Ma ${ }^{1}$ and Kar Way Tan ${ }^{2}$ \\ 1. Singapore University of Social Sciences, School of Business, Singapore \\ 2. Singapore Management University, School of Information Systems, Singapore
}

\begin{abstract}
Human's impact on earth through global warming is more or less an accepted fact. Ocean freight is estimated to contribute 4-5\% of global carbon emissions. Many manufacturing companies that transfer ship goods through full container loads found themselves under-utilizing the containers and resulting in higher carbon footprint per volume shipment. One of the reasons is the choice of non-ideal container sizes for their shipments. In this paper, we first provide an Integer Programming model to minimize the companies' shipping carbon footprints by selecting the ideal container sizes appropriate for their shipment volumes. Secondly, we proposed a strategy to minimize the carbon footprint by consolidating the shipments in the same country from multiple domestic locations at a port of loading by road freight, before the international sea shipment. A mixed-Integer Programming model has been developed to determine if one should ship each shipment separately or have shipments consolidated first before being shipped. Consolidation fills up the containers more efficiently that reduces the overall carbon footprint. Computational results using real-world data indicates a significant $13.4 \%$ reduction carbon emission when selecting the optimal combinations of different sizes of containers and an additional $12.1 \%$ reduction in carbon emission when shipment consolidation is applied.
\end{abstract}

Key words: Carbon emission, data analytics, container consolidation, sustainability, optimization, ocean freight, supply chain management

\section{Introduction}

Manufacturing companies may choose to ship their products using a third-party logistics service provider (LSP) by purchasing a full container; this is known as the Full Container Load (FCL). Using FCL means they will be responsible for the packing of the container. After packing the container, the logistics service provider will be responsible for transporting the container from the packing site to the final destination. Unfortunately, companies may not be able to maximize the utilization of the container's capacity. A typical company with varying trade volumes may order a fixed set of containers per shipment period (e.g., weekly, monthly) by contract and fill them up with whatever demands, resulting in low container capacity fill during low demand periods, larger total number of shipments and thus a higher total carbon

Corresponding author: Nang Laik Ma, senior lecturer. footprint due to the larger number of shipments. We observed from our data from a real-world LSP that the phenomenon of less-than-ideal container capacity fill is common. Another shipping option for companies is known as less-than-container load (LCL). In this situation, whatever volume of goods required to be shipped is passed to the LSP and the LSP will be responsible for moving the goods, the size and fill rate of the container is transparent to the customer. It is common for companies to use a combination of FCL and LCL to meet their shipping needs.

Unfortunately, often, companies using FCL may not be able to maximize the utilization of the container's capacity. This could be due to varying transportation volume or lack of consolidation capabilities. Companies may order fixed sets of containers for each manufacturing site in shipment period (e.g., weekly, monthly) based on contract terms. Containers are filled up with whatever demands, 
resulting in low container capacity fill during low demand periods. Inefficient use of containers, thus results in a total carbon footprint being higher than necessary.

Carbon footprint in this paper refers to the total amount of carbon emissions for all shipments via sea and land transportations. Typically, actual carbon footprint of particular shipment takes into account of various factors such as carbon efficiencies of the ship, type of fuel used and routes taken. For the purpose of this study, we are interested in comparing carbon emission contributed by the number and sizes of container used. As such, detailed calculation of carbon footprint is not necessary. Instead, carbon consumption ratio is used, e.g., the carbon consumption ratio of container per kilometer $(\mathrm{km})$ for 20-foot standard container (20FT), 40-foot standard container (40FT), and 40-foot high-cube (40HC) container is $1: 2: 2.2$. This ratio is realistic based on our domain knowledge carbon accounting of sea freight.

The objective of this paper is to support decisions on selection of appropriate combination of container sizes and shipment consolidation for a manufacturing company. The two-steps model which first takes the volumes to be shipped as an input and provide the combination of container sizes required; then evaluate possibility of shipment consolidation from multiple ports (of loading) within the same country to the same destination (port of discharge). In both steps, the objective function is to minimize carbon footprint by applying linear/integer programming. Only consolidation within the same country is considered due to practical considerations to avoid the need for cross border clearances.

We verify our model with a real-world business case (and data) in the consumer product manufacturing industry. By applying the proposed approach and models, the company can reduce the carbon footprint by $13.4 \%$ by using the optimal container size and further reduce the carbon footprint by $12.1 \%$ from consolidation of shipments as compared to the current practice without optimization.

Our model had been implemented by using AIMMS (Advanced Interactive Multidimensional Modeling System) which supports linear/integer programming. We believe that our approach and implementation technology can be easily adopted by various transportation companies in the industry.

In the next few sections, we discuss the literature review and identify gaps; followed by current business problems. We propose two-steps optimization models on selection of appropriate combination of container sizes and shipment consolidation for a manufacturing company. The approach yields better results in term of carbon emission and container size requirement. We also present some computational result and performance of the models. Finally, we discuss about model implementation in the company using the model proposed and future work to be done as a conclusion.

\section{Literature Review}

In 2012, Dekker, Bloemhof \& Ioannis [1] covered an overview on operations research for green logistics that contributes in terms of the background of containerization, containers and the container related activities. It also covers how to do some variables affect the carbon footprint of the shipment. No optimization model was presented to reduce the carbon footprint of the shipment.

Other studies done with the focus from a sustainability or green point of view are Lirn, Lin \& Shang (2014) [2] whom focused on green shipping management capability and Wuisan \& Wageningen (2010) [3] on green shipping through private governance, hence not to be widely adopted.

There are many difficulties in calculating the actual carbon footprint of particular shipment as the efficiency of the ship differs between them as well as the different routes that may have been taken between two ports. Leonardi \& Browne (2009) [4] developed a method for assessing the carbon footprint of ocean 
freight, but not an optimization problem. For the purpose of our optimization model, we found that detailed method for calculating carbon footprint is not necessary. To determine the optimal number of containers and their sizes, a ratio of carbon consumption of the various types of containers is sufficient, e.g., the carbon consumption ratio of container types 20FT: 40FT : $40 \mathrm{HC}$ is $1: 2: 2.2$. Using ratio simplifies the computations of the optimization model.

Another area of research is the container-packing problem. Thapatsuwan, Pongcharoen, Hicks \& Chainate (2012) [5] have developed algorithms to solve packing rectangular boxes into a set of containers. In their scenario, the size of the containers was fixed. Another work by Jin, Ohno \& Du (2002) [6] looked into solving the container-packing problem with additional practical constraints such as loading stability, the rotation of items around the height axis, and the fixed loading (unloading) orders. None of these works relate to computation of container sizes.

There is another collection of work on freight consolidation and containerization. In the domain of procurement, Mark et al., (2009) [7] presented a concept called lean procurement through the application of procurement consolidation techniques. This is to reduce transportation cost and to improve production efficiency in the supply chain for small-to medium-sized enterprises (SMEs).A recent paper by Qin, Zhang, Qi \& Lim (2014) [8] constructed a model to solve issues with shipping from a port to multiple destinations after arriving at the port of discharge. This work did not consider environment sustainability. However, it is an interesting idea for future work with additional considerations of carbon emission.

To our best knowledge, none of the work in the literature considered selection of appropriate sizes of containers. This is a fundamental decision a manufacturing company needs to make if the company ships using FCL. In addition, our model is supported and validated with a real-world data set.

\section{Business Problem Description}

We are motivated by a real-world business case that manufactures a consumer product with major production plants in China. The goods are shipped to the US for sales. Goods are shipped by ocean freight and the containers selected for this study are the most common ones, namely, 20-foot standard container, 40-foot standard container, and 40-foot high-cube container. In reality, $100 \%$ usage of the container is rare due to packing issues and size of goods. We investigated using our data set it is possible to fill up to $\sim 95 \%$ of a container. Hence, we will use $95 \%$ fill rate as the highest possible fill rate in our analysis. Table 1 shows the available container volumes at the two different capacity fill rates.

In our model, we consider only those shipments that require more than one container i.e., shipments with total volumes greater than $71.78 \mathrm{~m}^{3}$. Shipments that have total volumes smaller than $71.78 \mathrm{~m}^{3}$ are excluded because we observed in the dataset that $65 \%$ of these shipments are using LCL mode or while the rest have already selected the right container size as it is a straightforward choice.

After filtering by the total volume, the remaining shipments have the following breakdown in Fig. 1.

The company's current practice is to ship the containers as and when there is demand (orders from US) and it is usually shipped from a port of origin (port near manufacturing plant in China) to a destination port (in US) directly. We found in the data that there is a potential to better fill the containers with better selection of combination of containers of different sizes.

Table 1 Container volumes at different fill rates.

\begin{tabular}{llll}
\hline & $20 \mathrm{FT}$ & $40 \mathrm{FT}$ & $40 \mathrm{HC}$ \\
\hline Maximum container volume (cubic meters) & 33.2 & 66.7 & 76.2 \\
$\sim 95 \%$ container volume (cubic meters) & 31.5 & 63.4 & 72.4 \\
\hline
\end{tabular}




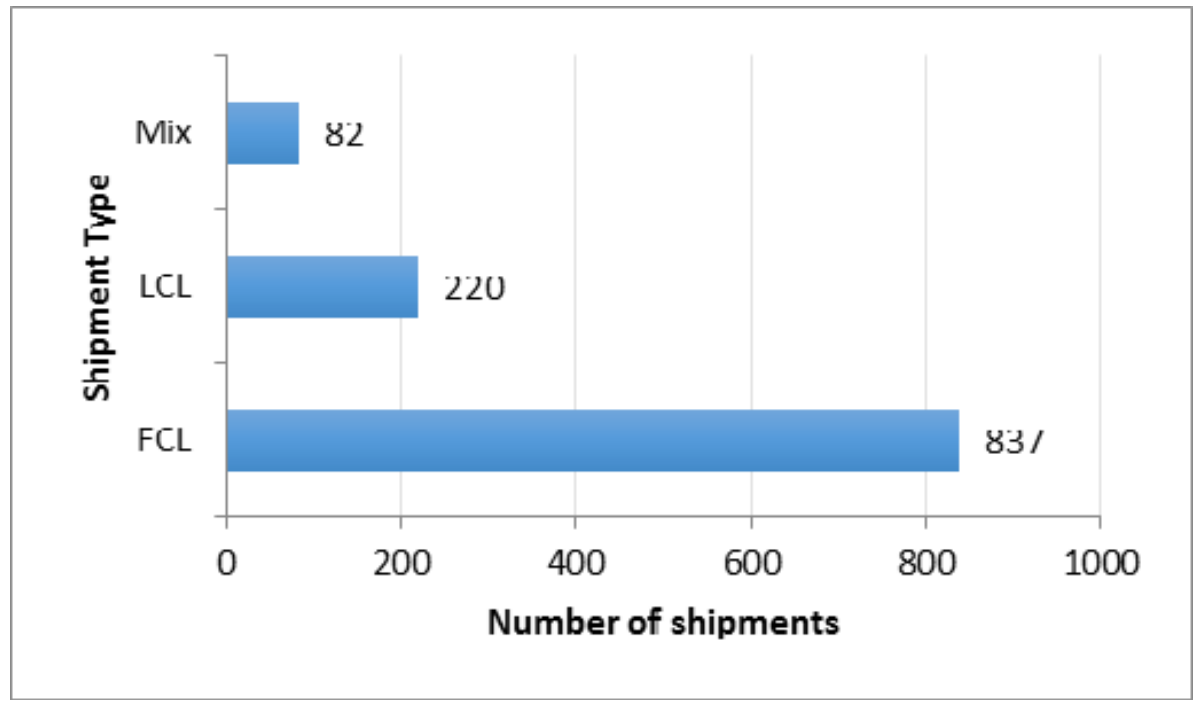

Fig. 1 Distribution of shipment types.
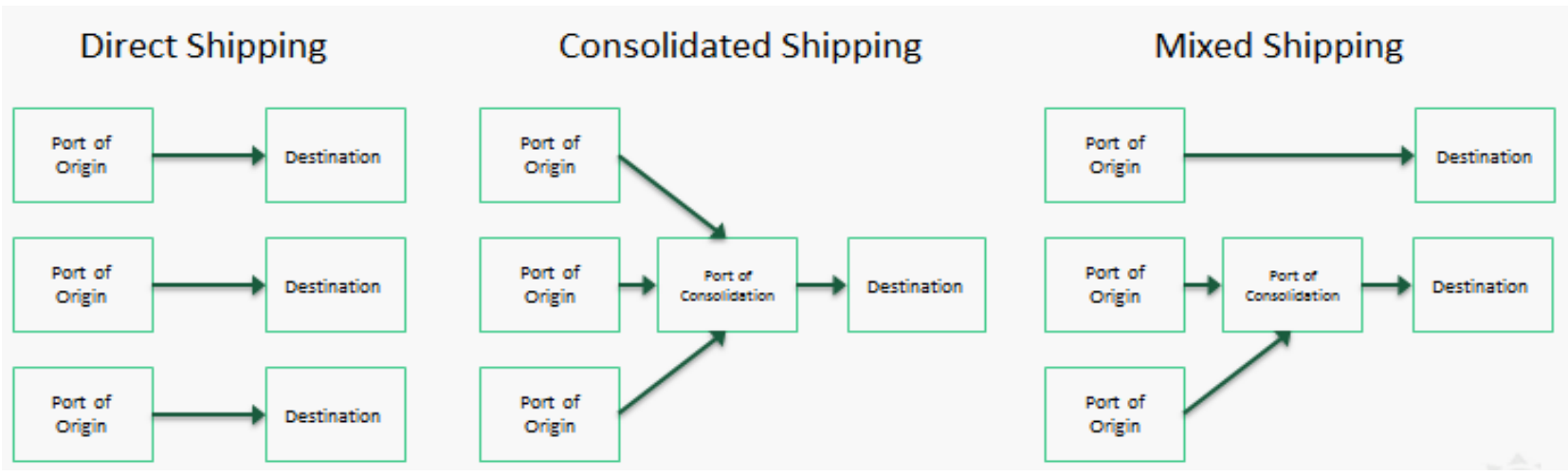

Fig. 2 Three possibilities of shipping.

We propose an integer programming model for Container Size Optimization (CSO) problem that optimizes the carbon footprint by considering both the selection of ideal sizes of containers for the shipment volume. The model also determines the optimal number of containers that satisfies the shipment volume. In CSO, we assume that the shipments can only be shipped directly from ports of loading (i.e., a port in China) to ports of discharge (i.e., in U.S) via sea. The idea is that it is more carbon efficient to use a set of containers which is just enough for the shipment volume as different container sizes has different carbon emission factors.

To further improve carbon emission factors, we also propose consolidation of shipments within a country (CSC). CSC combines shipments from different ports of origin within a country to a single consolidation port. A scenario is considered for CSC only when there is more than one shipment (from different manufacturing plants) on a single day. For each shipment, we provide an option to transport the goods from the manufacturing plant by road (truck) to a port of consolidation or be shipped directly from the port of origin. The options are mutually exclusive.

Our consolidation model takes the total volume to be shipped of all shipments (from various ports of loading), origin and destination as inputs. The output of the model minimizes the overall carbon footprint and provides 3 possibilities (Fig. 2): (1) direct shipment from original port of loading; (2) use road freight to consolidate all shipments at a single port of loading in the same country; (3) combination of direct and consolidated shipment. In the case of consolidation (Options 2 and 3), the model will also 
provide the most suited port of loading.

\subsection{Methodology: Mathematical Models}

Integer programming is used to solve the container size (CSO) problem. There are a few assumptions made: (1) companies can pack up to $95 \%$ of the container volume. (2) All shipments are made through FCL. (3) Required containers (of the various sizes as determined by CSO) are always available. (4) The weight of the shipment does not impact the carbon footprint of the containers (which is the industry carbon accounting method for ocean freight).

\section{Carbon Emission Factor}

The amount of carbon emission per container $\mathrm{km}$ on container ships is a complex calculation based on many factors such as efficiency of the ship, fuel used, ship cruising speed, tidal conditions and actual route taken. For example, the older ships are less fuel-efficient and hence emit more carbon dioxide than the newer ships which emit between 20-40\% less carbon dioxide. Actual carbon emission of the same container shipped on different ships has large variances. For the purpose of our optimization model, instead of using the actual carbon emission number, we found that a comparison factor is sufficient to compare the options of using different sizes of containers. We use a pre-determined carbon emission ratio for each of the three sizes of container. In this way, we assume that given the same shipping conditions (e.g., vessel used, route, and speed), the only factors affecting the carbon footprint are the type and number of containers used for the shipment.

The carbon emission factors we considered are as follows: the 40-foot standard container emits twice the amount of carbon dioxide of a 20-foot standard container and a 40-foot high-cube container emits $10 \%$ more carbon dioxide than a 40 -foot standard container. Therefore, in our model we shall use the ratio of 1:2:2.2 for 20FT: 40FT: $40 \mathrm{HC}$. This ratio shows that for ocean shipments, the 20-foot standard and 40-foot standard containers actually have the same carbon footprint per cubic meter. With the same carbon footprint per cubic meter, the shipment volume becomes the main determining factor in selecting which type of container is most appropriate.

In our data set, each row (a data point) is a shipment with an associated shipment volume from a port of origin to a port of destination. CSO is applied on each row of shipment volume. If a shipment is being consolidated, CSO is also applied on the consolidated volume.

\section{Container Size Optimization (CSO) Model}

The following variables will be used in CSO model: $i=$ Type of container size, 1 for $20 \mathrm{~S}, 2$ for $40 \mathrm{~S}$ and 3 for $40 \mathrm{HC}, \forall i=1,2,3$;

$j=$ Port of loading, $\forall \mathrm{j}=1,2,3 \ldots n$;

$\mathrm{k}=$ Port of discharge, $\forall \mathrm{k}=1,2,3 \ldots m$;

$C_{i}=$ Carbon Emission per container $\mathrm{km}$ for each container size;

$Q_{j k}=$ Shipping distance between port of loading and port of discharge in $\mathrm{km}$;

$V_{i}=$ Volume for each size of container;

$S_{j k}=$ Volume to be shipped on each trade lane $(j, k)$, where trade-lane is a pair of unique port of loading and port of discharge;

$E=$ Maximum excess volume set to $10 \mathrm{~m}^{3}$ for this model.

Decision variable:

$X_{i j k}=$ Number of containers of size $i$ for port of loading $\mathrm{j}$ and port of discharge $k$.

The objective function is to minimize:

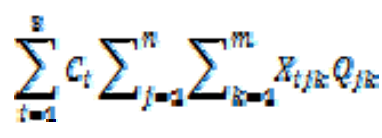

Subject to:

$$
\begin{aligned}
& \sum_{t=1}^{2} V_{t} X_{i z} \geq s_{j 2} \quad \forall p_{i} k \\
& \sum_{t=1}^{n} V_{t} X_{t / 2}-S_{j:} \leq E \quad \forall t, k
\end{aligned}
$$$$
Z_{i / \mathrm{k}} \in Z^{+}
$$

The problem is to find the best mix of containers with the objective of minimizing the total carbon 
footprint. Total carbon footprint is the summation of the emission factors of the shipments.

Constraint 1 ensures that the required volume is met by mandating that the optimized volume across the containers be equal or larger than the required volume for each trade lane represented by $j$ and $k$. Constraint 2 takes into account to minimize excess volume of the optimized solution. Set to an arbitrary upper limit of $10 \mathrm{~m}^{3}$ for this model, the problem will be solved when the optimized containers selected have a total sum of less than or equal to $10 \mathrm{~m}^{3}$ of excess volume. The reason for including such a constraint is to ensure that the model provides a solution with minimal excess space. We note that there is a possibility that this constraint cannot be met and results in no solution.

\section{Consolidation of Shipment within Country (CSC)}

Mixed-Integer programming is used to solve CSC. The intuition for this optimization is to enable shippers to consolidate shipments at one port of loading and in doing so, increase the capacity fill per container in order to reduce their carbon footprint. The model takes into consideration all shipments which are heading to the same port of discharge. It is possible that the selected port of consolidation is one close to where the goods are produced, or a port that is purely used for consolidation. For example, goods are produced in $\mathrm{A}$ and $\mathrm{B}$, but they can be consolidate at port E. Consolidation port is one which gives the lowest trucking and shipping carbon footprint to the port of destination. There are 2 sets of decision variables, the first set involves binary decisions on whether a particular shipment should be shipped directly or consolidated, and the second set of decision variables is to determine the optimal container sizes and number of each container size required while minimizing the overall carbon footprint.

The additional carbon emissions that have to be taken into account for the consolidation model are the carbon emissions that stem from trucking the goods between original and consolidation locations. Similar to shipping, the exact carbon emission per cubic meter per kilometer $(\mathrm{km})$ for trucking is influenced by the fuel efficiency of the truck, the type of truck, and the fill capacity. For the purpose of comparisons, a fixed factor is proposed for our optimization model. Based on industry input, we used an emission factor (no unit) of 0.011 for trucking a volume of $1 \mathrm{~m}^{3}$ per $\mathrm{km}$.

The additional variables that have to be taken into account are:

- The trucking distance between cities;

- The trucking carbon emission for $1 \mathrm{~m}^{3}$ per $\mathrm{km}$.

There are a few assumptions made for CSC:

- The original trucking distance between supplier/manufacturer and the original port of loading (before consolidation) is negligible and hence set to 0 ;

- Production schedule of goods can be shifted to accommodate the additional time required for trucking the goods to the port of consolidation;

- There is no additional time required for loading and unloading the goods from the truck;

- The goods are transported via Less-than-Truck-Load (LTL) and hence the resulting trucking carbon emission is dependent purely on the volume of the goods. As the goods are transported via LTL to port of consolidation, it makes sense for CSO to be applied after CSC to determine the optimal mix of containers to be selected for the final consolidated shipment;

- Transportation is always available for trucking between two locations.

The following variables are used in CSC model:

$i=$ Type of container size, 1 for $20 \mathrm{~S}, 2$ for $40 \mathrm{~S}$ and 3 for $40 \mathrm{HC}, \forall i=1,2,3$;

$j=$ Port of loading, $\forall j=1,2,3 \ldots n$;

$\hat{\jmath}=$ Port of consolidation, it will be one of the port of loading $, \forall \hat{\jmath}=1,2,3 \ldots n$;

$k=$ Port of discharge, $\forall k=1,2, . ., m$;

$C_{i}=$ Carbon Emission per container $\mathrm{km}$ for each container size;

$V_{i}=$ Volume for each size of container;

$T=$ Trucking carbon emission for $1 \mathrm{~m}^{3}$ per $\mathrm{km}$; 
$P_{j \hat{j}}=$ Trucking distance between supplier/ manufacturer and port of consolidation in $\mathrm{km}$;

$Q_{j k}=$ Shipping distance between port of loading and port of discharge in $\mathrm{km}$;

$Q_{j k}=$ Shipping distance between port of consolidation and port of discharge in $\mathrm{km}$;

$S_{j k}=$ Volume to be directly shipped from each port of loading to one port of discharge;

$R_{j j k}=$ Volume to be trucked from supplier/ manufacturer to port of consolidation and consolidated volume to be shipped to port of discharge (i.e., let the volume to be the same as $S_{j k}$ );

$D_{k}=$ Total volume expected at port of discharge.

Decision variables:

$X_{i j k}=$ Number of containers of size $i$ for port of loading $\mathrm{j}$ and port of discharge $k$;

$Y_{i j k}=$ Number of containers of size $\mathrm{i}$ for port of consolidation $\hat{\jmath}$ and port of discharge $k$;

$f_{i j k}=$ Binary decision variable for consolidation at port $\hat{j}$

$$
\begin{aligned}
& f_{\mathrm{j} k \mathrm{k}}= \begin{cases}1, & \text { if consaldate } \\
0, & \text { otherwise }\end{cases} \\
& \mathrm{g}_{\mathrm{jk}}=\text { Binary decision variable for direct shipping } \\
& g_{\mathrm{j} k \mathrm{k}}= \begin{cases}1, & \text { of drect shmpwng } \\
0, & \text { otherwise }\end{cases}
\end{aligned}
$$

The objective function is to minimize carbon emission from direct shipping and consolidated shipping (ocean transport and trucking from each city to port of consolidation):

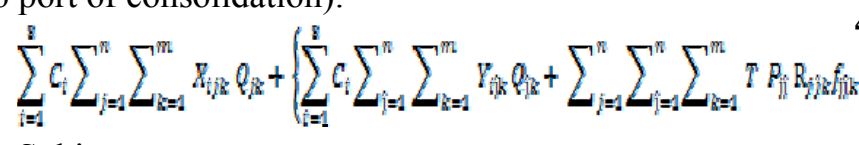

Subject to:

$$
\begin{aligned}
& 1-\left(\Sigma_{j-1} f_{j k}+g_{f 2}\right)=0
\end{aligned}
$$

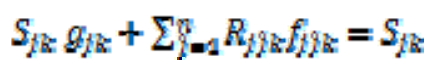

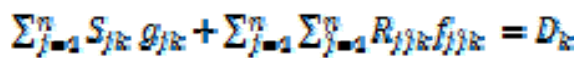

$$
\begin{aligned}
& \sum_{i=1}^{3} V_{i} X_{i j k}+\sum_{i=1}^{3} V_{i} Y_{i \hat{j} k} \geq S_{j k} g_{j k}+
\end{aligned}
$$

$\sum_{j=1}^{n} R_{j \hat{\jmath} k} f_{j \hat{j} k}$

$f_{j \in k} \in\{0,1\}$

$g_{i z:} \in\{0,1\}$

$X_{t ; z} \in Z^{+}$
$Y_{\hat{f} \mathrm{k}} \in Z^{+}$

In the objective function, the first term is the total carbon emissions for direct shipping. The second term considers the carbon emissions due to trucking the goods for consolidation and the ocean freight carbon emissions from the port of consolidation to port of discharge.

Constraint 3 ensures that for each shipment within the consolidation problem can only be either shipped directly or consolidated at the port, and it is a mutually exclusive event (i.e. a shipment has to be shipped directly or consolidated - no partial shipment is allowed). Constraint 4 denotes total volumes shipped directly and consolidated through the loading port is the same with the total supply. Constraint 5 ensures that the total volume that the port of discharge receives is equal to the total volume to be sent directly and from multiple loading ports to the same port of discharge. Constraint 6 ensures that the required volume for each trade lane for direct shipping plus any consolidated volume is met by the optimal number of containers of each size required.

Our model assumed that there is a linear relationship between the variables and we have unlimited number of containers at our disposal. We are also able to choose the port of loading based on the most carbon-efficient routes given by the model without any political reason.

\section{Computational Results}

Our data from the real-world company consists of shipments between the period of April 2009 and December 2013 (4.5 years). In this data, $53 \%$ of the shipments originated from 10 different ports in China and majority of the finished goods were shipped to 14 ports in U.S. As both source and destination countries are large countries with multiple sea ports across different geographical locations, we found opportunities to apply CSC and CSO methods.

In order to perform consolidation, shipments from different cities need to be heading towards the same 
port of discharge. We found that $97.5 \%$ of the shipments arrived at 4 major ports J, K, L, M (names of ports being masked out for data protection purposes). We assume that shipment arrival dates (at destination port) cannot be changed due to business needs. In order to consolidate, there must be same-day shipments to the same destination port. We found a total of 380 possible consolidation scenarios in our data set. For the shipments with only a single shipment for the day, only CSO is applied. Among the CSO scenarios, we considered only those shipments that require more than one container, i.e., shipments with total volumes greater than $71.78 \mathrm{~m}^{3}$. Shipment with volumes smaller than $71.78 \mathrm{~m}^{3}$ is trivial as the selection of right container size is a straightforward choice. In our data set, we found 837 cases of single shipments satisfying the volume required for CSO.

The experiment was executed in three steps. In the first step, we solved single shipments for container size optimization using the CSO Integer programming model. Secondly, we solved the shipments with multiple single-day shipments using the CSC Mixed-integer programming model. Finally, for the consolidated shipments, we applied CSO to the final consolidated volume to find the optimal mix of container sizes required. All problems were solved using AIMMS optimization software.

Out of the 837 problems in step 1 of our experiment using CSO model, 228 of them could not be solved within the maximum excess volume of $10 \mathrm{~m}^{3}$. The group of 228 problems was solved by relaxing the excess volume constraints. Our results revealed a total of $13.4 \%$ reduction of carbon footprint from almost $80 \%$ of shipments (total of 665 shipments). Of the 665 shipments that had carbon footprint reduction, there was a $15 \%$ reduction in container requirements in terms of number of TEU (see Table 2). Putting the savings into perspective, through the use of a carbon calculator provided by (BSR and CCWG, 2014), assuming that a 20 -foot standard container (a TEU) emits 63 grams of $\mathrm{CO} 2$ per TEU kilometer per container $\mathrm{km}$ and the average shipment distance is $10,000 \mathrm{~km}$, the company would have reduced a total of 488 thousand $\mathrm{KG}$ of its carbon footprint, which is the equivalent of taking off 95 cars off the road for a year.

In step 2, we solved the 380 problems from 8 China ports of loading to the 4 destination ports J, K, L and M. Our results revealed that $98.7 \%$ of shipments ( 375 out of 380) had the potential of reducing its carbon footprint by consolidating. For the purpose of isolating the performance of CSC, we tested two more scenarios on the 380 problems. In the first scenario, we apply CSO to individual shipments only (step 1 only). In the second scenario, we applied CSC followed by CSO (step 2 and 3). We tabulated the results in Table 3, showing that CSC provides an additional savings of $12.1 \%$ in carbon footprint on top

Table 2 CSO gives $15 \%$ reduction of container requirements.

\begin{tabular}{llll}
\hline Container size & Original container requirements (in TEU) & Optimal container requirements (in TEU) & $\%$ Change \\
\hline 20 FT & 368 & 602 & $64 \%$ \\
40 FT & 2128 & 1824 & $-14 \%$ \\
40 FT HC & 2611.4 & 1907.4 & $-27 \%$ \\
\hline
\end{tabular}

Table 3 Additional $12.1 \%$ reduction in carbon emission provided by CSC.

\begin{tabular}{ll}
\hline Port of Discharge & Total \% Change \\
\hline $\mathrm{J}$ & $-11.70 \%$ \\
$\mathrm{~K}$ & $-11.50 \%$ \\
$\mathrm{~L}$ & $-12.30 \%$ \\
$\mathrm{M}$ & $-28.10 \%$ \\
Total & $-12.10 \%$ \\
\hline
\end{tabular}


of the savings achieved by CSO.

We anticipated that the carbon emission factor for trucking may affect the performances of CSC. Therefore, we performed a sensitivity test to show the differences if the carbon emission factor for trucking is varied between 0.005 and 0.25 . Only 1 scenario of a decrease from the baseline of 0.011 (based on real-world estimation by a LSP) was taken because at 0.005 the model suggests that all shipments should have some form of consolidation since the emission from trucking is negligible.

We found a positive correlation between the trucking carbon emissions and the number of shipments that were consolidated. As the trucking carbon emissions increase, number of direct shipments increases, the number of full consolidation decreases. Mixed shipping started with a reasonable increase and then maintain somewhat constant. Overall, total percentage of trucking emissions decreases with increasing trucking emissions due to reduction in consolidation. Fig. 4 shows us the result.

The sensitivity analysis confirms our intuition that trucking emissions affect the decision to consolidate. The potential for consolidation diminishes with increasing trucking emissions. Consolidation represents an opportunity to reduce the total carbon footprint, but it is not without tradeoffs. One of which is that production scheduling may need some changes in order to accommodate trucking time required for consolidation. Truck deliveries can also be challenging for some geographical regions for the uncertainty in maintaining quality of products and keeping to shipping schedules.

\section{Model Implementation}

In order to make CSO optimization model widely available to companies and end-users, consideration of the software available and the ease of use have to be taken into account. In addition to the AIMMS model,

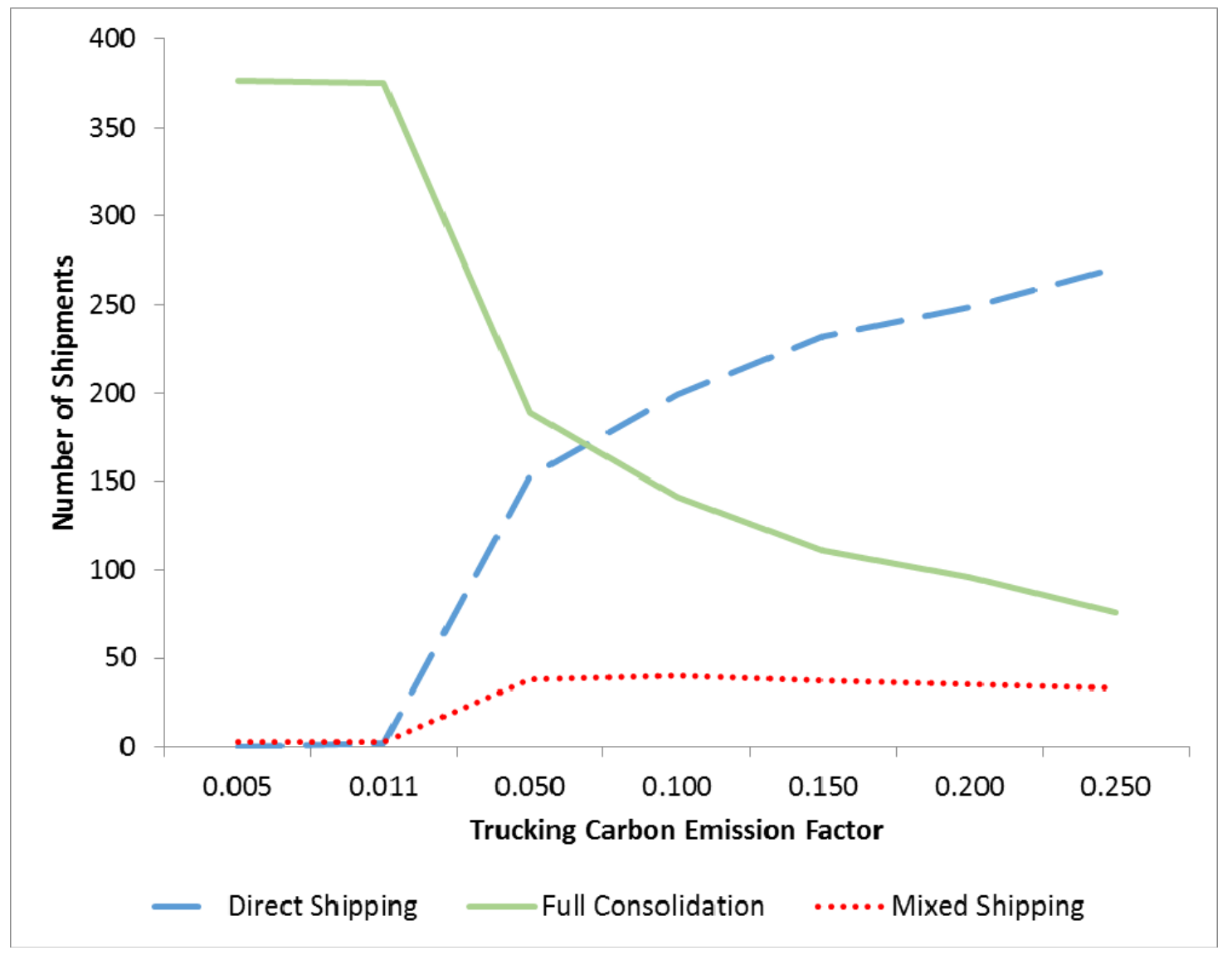

Fig . 4 Sensitivity analysis with different trucking emission factors. 
we have also developed a model using Microsoft Excel for smaller scale short-term planning. Microsoft Excel is the most commonly available software in companies and it provides solver as an optional add-in, therefore without any additional outlay of software investment or significant amount of training, users within a company should be able to quickly make use of the model.

The model is built on a spreadsheet with 3 user inputs: namely volume, the maximum percent of capacity fill, and the excess volume $\left(\mathrm{m}^{3}\right)$ limit. Two macros are written to enable users to clear the previous data and then run the solver once they have keyed in the data. The model is built to allow 7 rows of inputs, 7 has been chosen with the assumption companies use 1 row per day and therefore the model can support up to 1 week of planning. The time taken for solver to come up with a solution depends on the number of problems that need to be solved, the size of the shipment volume and the speed of the computer's processor. In our experiment using the shipment volume, the capacity fill percentage, and the maximum excess volume, a solution is produced within 10 minutes for the planning of 7 shipments.

Excel's default basic solver is capable of accepting up to 200 decision variables. 7 rows of input implies a total of 21 (7 X 3) decision variables, as the number of decision variables increase, the amount of time taken for solver to find a solution exponentially increases and therefore it is also a technical limitation that the model is confined to 7 rows. In addition, the time taken for solver to arrive at a solution is also highly dependent on the volumes, the larger the volume the longer the amount of time will be required.

Although in this paper the problems were solved using AIMMS optimization software, we understand that there is additional cost in acquiring the software and training required for personnel in order to operate it. Therefore, we provide Excel as an alternative software for wider adoption. On the other hand, companies looking to manage larger volumes than what the current Excel model can provide should look into investing in the software and training the people to be competent in modeling and running them to generate results for operations usage.

\section{Conclusions}

This paper has shown that there are opportunities for companies to reduce their supply chain carbon footprint. We proposed two optimization models to reduce carbon footprint by more efficient use of ocean freight containers. With container size optimization (CSO), which minimizes carbon emission by selecting the ideal container sizes, we showed with a real-world dataset that company has the potential to reduce $13.4 \%$ of their carbon footprint. Considering consolidation shipment within country (CSC) provides an additional opportunity of $12.1 \%$ reduction in carbon emission for the case company. We believe that the method and optimization model can be applied to another data set with similar observations such as large percentages of shipments (with multiple shipments on the same day) from multiple ports in the same country to a few major ports. To further this research, we recommend additional real-world considerations such as production schedules, trucking cost and constraints to be considered before making decision on shipment consolidation.

\section{Acknowledgments}

This work was supported by the Green Transformation Lab (a collaboration between DHL and Singapore Management University).

\section{References}

[1] Dekker, R., Bloemhof, J., and Mallidis, J. 2012. "Operations Research for Green Logistics - An Overview of Aspects, Issues, Contributions and Challenges." European Journal of Operational Research 219 (2012): 671-9.

[2] Lirn, T. C., Lin, H. W., and Shang, K. C. 2014. "Green Shipping management Capability and Firm Performance in the Container Shipping Industry." Maritime Policy \& Management: The Flagship Journal of International 
Shipping and Port Research 201441 (2): 159-75.

[3] Wuisan, L., Leeuwen, J., and Koppen, K. 2012. "Greening International Shipping through Private Governance: A Case Study of Clean Shipping Project." Marine Policy 36 (2012): 165-73.

[4] Leonardi, J., and Browne, M. 2009. "A Method for Assessing the Carbon Footprint of Maritime Freight Transport: European Case Study and Results." International Journal of Logistics Research and Applications: A Leading Journal of Supply Chain Management 13 (5): Special Issue: Logistics Research Network (LRN 2009).

[5] Thapatsuwan, P., Pongcharoen, P., Hicks, C., and Chainate, W. 2012. "Development of a Stochastic Optimization Tool for Solving the Multiple Container
Packing Problems." International Journal Projection Economics 140 (2012): 737-48.

[6] Jin, Z., Ohno, K., and Du, J. 2004. "An Efficient Approach for the Three-Dimensional Container Packing Problem with Practical Constraints." Asia-Pacific Journal of Operational Research 21 (03): September 2004.

[7] Mark, M. J., Wilson, R., and Ram N. 2009. "Enabling Lean Procurement: A Consolidation Model for Smalland Medium-sized Enterprises." Journal of Manufacturing Technology Management 20 (2009): 817-33.

[8] Qin, H., Zhang, Z., Qi, Z., and Lim, A. 2014. "The Freight Consolidation and Containerization Problem." European Journal of Operational Research 234 (2014): $37-48$. 